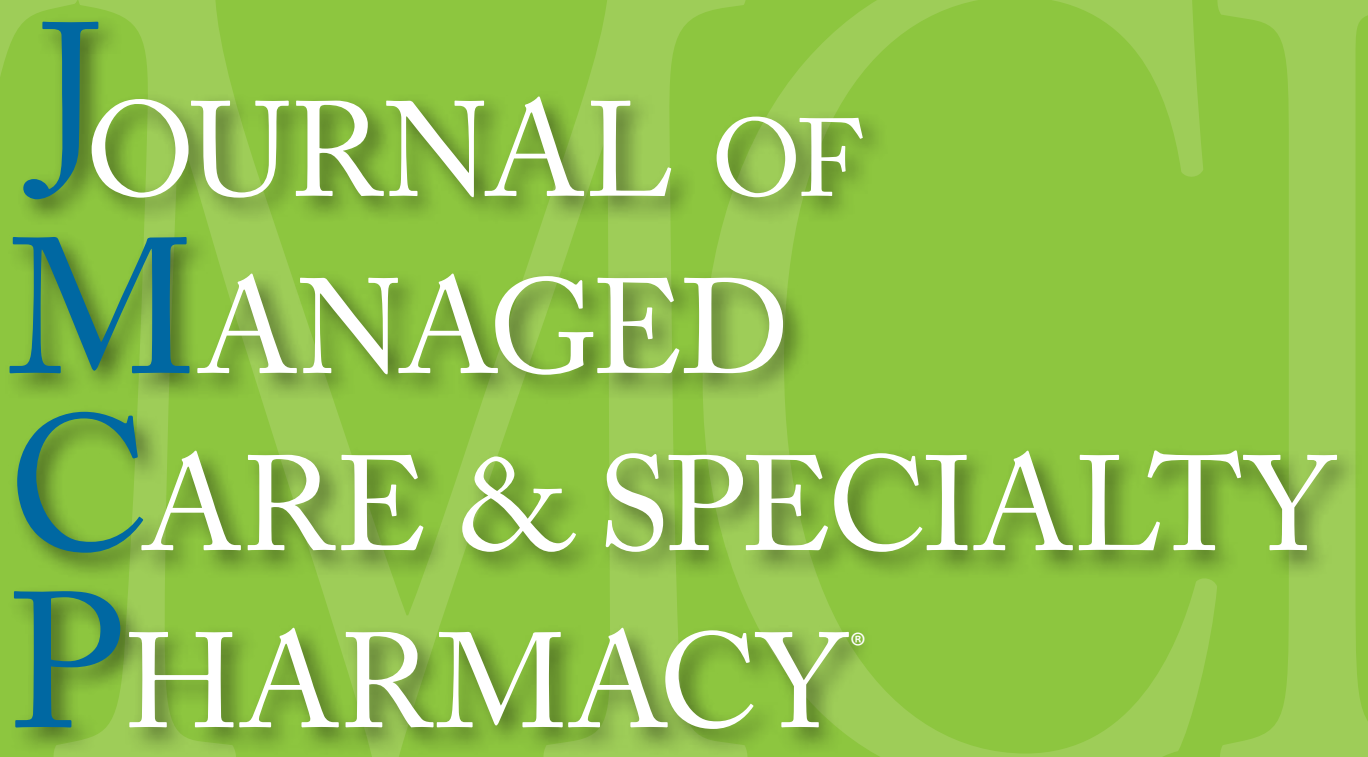

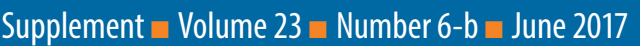

\title{
The Emerging Role of Pimavanserin in the Management of Parkinson's Disease Psychosis
}

Neal Hermanowicz, MD; Gustavo Alva, MD; Fernando Pagan, MD; Alberto J. Espay, MD, MSc; Amita Patel, MD, CMC, MHA, CPE; Katya Cruz Madrid, MD; Daniel Kremens, JD, MD; Jim Kenney, RPh; Sheila Arquette, RPh; Gary Tereso, PharmD, BCPS; Maria Lopes, MD; and Carolyn Farnum, BS 


\section{MCP}

Publisher

Susan A. Cantrell, RPh, CAE

Chief Executive Officer

Academy of Managed Care Pharmacy

\section{Editor-in-Chief}

Laura E. Happe, PharmD, MPH

864.938.3837; lhappe@jmcp.org

\section{Assistant Editor}

Robert P. Navarro, PharmD

University of Florida College of Pharmacy

Gainesville, FL

\section{Assistant Editor}

Karen L. Rascati, PhD

University of Texas College of Pharmacy

Austin, TX

\section{Assistant Editor}

Karen M. Stockl, PharmD

OptumRx, Irvine, CA

\section{Managing Editor}

Jennifer A. Booker

703.317.0725; jmcpreview@amcp.org

\section{Production Editor}

Carol Blumentritt

602.616.7249; cblumentritt@amcp.org

\section{Graphic Designer}

Margie C. Hunter

703.297.9319; mhunter@amcp.org

\section{Account Manager}

Jen Callow, American Medical Communications, Inc. 732.580.8884, JCallow@americanmedicalcomm.com

This supplement to the Journal of Managed Care \& Specialty Pharmacy (ISSN 2376-1032) is a publication of the Academy of Managed Care Pharmacy, 675 North Washington St., Suite 220, Alexandria, VA 22314; 703.684.2600

Copyright $\left({ }^{\circ}\right.$ 2017, Academy of Managed Care Pharmacy. All rights reserved. No part of this publication may be reproduced or transmitted in any form or by any means, electronic or mechanical, without written permission from the Academy of Managed Care Pharmacy.

POSTMASTER: Send address changes to JMCP,

675 North Washington St., Suite 220, Alexandria, VA 22314

\section{Supplement Policy Statement}

\section{Standards for Supplements to the}

Journal of Managed Care \& Specialty Pharmacy Supplements to the Journal of Managed Care \& Specialty Pharmacy (JMCP) are intended to support medical education and research in areas of clinical practice, health care quality improvement, or efficient administration and delivery of health benefits. The following standards are applied to all JMCP supplements to ensure quality and assist readers in evaluating potential bias and determining alternate explanations for findings and results.

1. Disclose the principal sources of funding in a manner that permits easy recognition by the reader.

2. Disclose the existence of all potential conflicts of interest among supplement contributors, including financial or personal bias.

3. Describe all drugs by generic name unless the use of the brand name is necessary to reduce the opportunity for confusion among readers.

4. Identify any off-label (unapproved) use by drug name and specific off-label indication

5. Strive to report subjects of current interest to managed care pharmacists and other managed care professionals.

6. Seek and publish content that does not duplicate content in the Journal of Managed Care \& Specialty Pharmacy.

7. Subject all supplements to expert peer review.

\section{AUTHORS}

Neal Hermanowicz, MD

Director, Movement Disorders Program, and Vice Chair, Clinical Affairs, Department of Neurology, University of California Irvine Health, Irvine, CA

Gustavo Alva, MD

Psychiatrist, Chapman Global Medical Center, Orange, CA; ATP

Clinical Research, Costa Mesa, CA; and University of California,

Riverside, Orange, CA

Fernando Pagan, MD

Vice Chair, Department of Neurology; Director, Movement Disorders Program; Medical Director, Georgetown University Hospital National Parkinsonism Foundation Center of Excellence; and Medical Director, Translational Neurotherapeutics Program, Georgetown University,

Washington, DC

Alberto J. Espay, MD, MSc

Associate Professor, Department of Neurology and Rehabilitation Medicine, University of Cincinnati Gardner Neuroscience Institute, Cincinnati, $\mathrm{OH}$

Amita Patel, MD, CMC, MHA, CPE

Psychiatrist, Institute for Psychiatric Education, Dayton Psychiatric Association, Dayton, $\mathrm{OH}$

Katya Cruz Madrid, MD

Associate Professor of Medicine, Division of Academic Internal Medicine and Geriatrics, University of Illinois, and Physician, Jesse Brown

Veterans' Center, Chicago, IL

Daniel Kremens, JD, MD

Associate Professor and Codirector, Movement Disorders Program, and Clerkship Director, Department of Neurology, Jefferson University, Philadelphia, PA

Jim Kenney, RPh

Manager, Specialty and Pharmacy Contracts, Harvard Pilgrim Health Care, Quincy, MA

Sheila Arquette, RPh

Director, Pharmacy Services, Independent Health, Buffalo, NY

Gary Tereso, PharmD, BCPS

Senior Clinical Pharmacist, Health New England, Springfield, MA

Maria Lopes, MD

Medical Director, Magellan Rx Management, Newport, RI

Carolyn Farnum, BS

Senior Market Research Manager, Magellan Rx Management, Newport, RI 


\section{Table of Contents}

\section{The Emerging Role of Pimavanserin in the Management of Parkinson's Disease Psychosis}

Neal Hermanowicz, MD; Gustavo Alva, MD; Fernando Pagan, MD;

Alberto J. Espay, MD, MSc; Amita Patel, MD, CMC, MHA, CPE; Katya Cruz Madrid, MD;

Daniel Kremens, JD, MD; Jim Kenney, RPh; Sheila Arquette, RPh; Gary Tereso, PharmD, BCPS;

Maria Lopes, MD; and Carolyn Farnum, BS

\section{S2 PDP Background}

S3 The Societal Burden of PDP

\section{S4 PDP Treatment}

S5 Panel Recommendations

\section{S7 Future Considerations}

\section{Disclosures}

This project and manuscript was funded by ACADIA Pharmaceuticals and developed by Magellan Rx Management. ACADIA Pharmaceuticals is the manufacturer of NUPLAZID (pimavanserin). 


\title{
The Emerging Role of Pimavanserin in the Management of Parkinson's Disease Psychosis
}

\author{
Neal Hermanowicz, MD; Gustavo Alva, MD; Fernando Pagan, MD; Alberto J. Espay, MD, MSc; \\ Amita Patel, MD, CMC, MHA, CPE; Katya Cruz Madrid, MD; Daniel Kremens, JD, MD; \\ Jim Kenney, RPh; Sheila Arquette, RPh; Gary Tereso, PharmD, BCPS; Maria Lopes, MD; \\ and Carolyn Farnum, BS
}

\begin{abstract}
SUMMARY
A panel of experts drawn from neurology, psychiatry, geropsychiatry, geriatrics, and pharmacy representatives of 3 health plans convened in New York City on July 30,2016 , with the objective of sharing opinions, ideas, and information regarding the optimal management of Parkinson's disease psychosis (PDP). Three key points emerged from the discussion: (1) Because of the nature of Parkinson's disease and PDP, finding appropriate treatment can prove challenging; (2) emerging therapies may present an opportunity for effective disease management; and (3) moving forward, provider and patient education regarding PDP and available treatment options is essential for wellmanaged symptoms and better quality of life.

The panel reviewed current practices and formulated recommendations on moving forward in the treatment of PDP.
\end{abstract}

J Manag Care Spec Pharm. 2017;23(6-a):S2-S8

Copyright $\odot 2017$, Academy of Managed Care Pharmacy. All rights reserved.

$\mathrm{P}$ arkinson's disease (PD) affects approximately 1 million Americans and is becoming increasingly common, with an anticipated doubling of cases worldwide by $2030 .{ }^{1}$ Although often regarded as an illness of the elderly, Parkinson's disease is perhaps best described as a disease of the mature, with a median diagnosis age of 60 ; however, providers have observed cases in which patients have experienced the disease at an earlier age of onset, and half of all cases are below the median age of $60 .^{2}$

During the course of their illness, approximately $50 \%$ of patients with PD will develop a related condition known as Parkinson's disease psychosis (PDP), which, on average, is diagnosed 10 years following the initial diagnosis of $\mathrm{PD}^{3}$ The symptoms of PDP are often among the most disturbing features of PD to the patient and caregiver alike and are a leading cause of hospitalizations and long-term care placement in this population. ${ }^{4-6}$

The recognition of PDP symptoms by clinicians can be challenging and despite the disruption they bring, the symptoms are often overlooked or unaddressed. Previous PDP treatment approaches have required trial and error with non-PDP-specific therapies, many of which the panel noted had accompanying side effects that limited their use, supporting the need for a new PDP therapeutic intervention. ${ }^{2}$ To address this, pimavanserin (NUPLAZID) was developed for the treatment of hallucinations and delusions associated with PDP and received U.S. Food and Drug Administration (FDA) approval for the treatment of these common and often troubling symptoms.
In light of projected increases in the incidence of PDP, recognized management challenges, and therapeutic advances, an expert panel was convened. The panel comprised individuals with diverse yet complementary expertise in neurology, psychiatry, geropsychiatry, and geriatrics. All contributors had firsthand experience with identifying and managing PDP. The sharing of insights as attained in a variety of clinical practice settings provided a solid foundation for the panel regarding meeting the challenge and opportunities to improve the management of PDP.

\section{PDP Background}

The symptoms of PDP have striking characteristics and consist of delusions and hallucinations. ${ }^{7}$ With hallucinations, which occur in about $30 \%$ of PDP patients, patients may see an object different from what it is, such as a fire hydrant appearing to be a child at the roadside, or they may see objects, animals, or people in the absence of any visual cue. ${ }^{7}$ The presence or passage of a person may be seen in a patient's peripheral vision. Animals, commonly insects, or small, furry creatures scurrying across the floor may appear. People, children or adults, strangers or people known, may be seen outside or within the home, wordlessly observing or, sometimes, menacing. Although visual phenomena are most common, hallucinations can involve any of the other senses, including hearing, smell, and touch. Running water may be heard as music or voices, or conversations may be heard when there is silence.

Delusions are another, less common but invariably more troubling feature of PDP, occurring in about 5\% of PDP patients. ${ }^{7}$ Delusions are beliefs held by an individual that are not based on reality and exist in the face of contrary evidence. Although not all inclusive, the delusions of PDP often fall into a few themes common among different patients. Such themes include spousal infidelity; threat of physical harm, including by medication poisoning by caregivers; and theft of possessions or finances. ${ }^{7}$

It was previously believed that PDP was a complication of PD treatment and that the medications used to alleviate motor symptoms, such as rigidity and bradykinesia, were the culprits of the psychosis symptoms. In fact, this impression still lingers today among some clinicians. The correlation between PDP hallucinations and medication type and amount has been inconsistent in the literature. Notably, hallucinations were not reproduced by intravenous infusion of levodopa, suggesting a weak link between PD treatments that influence levels of 
levodopa in the body and PDP. ${ }^{7-9}$ Further complicating the assessment of the role of PD treatments in PDP, proposed diagnostic criteria for PDP published by a National Institutes of Health work group in 2007 specifically indicate that PDP symptoms may occur in the absence of treatment with PD medications. $^{3}$

Although there is no definitive evidence of the precise role medications play in PDP, and they are always considered in the initial PDP patient assessment process, there is evidence that emergence of PDP symptoms appears dependent on individual patient pathology. Hallucinations have been found to be more common among people with Parkinsonism who were determined by postmortem examination to have evidence of neurodegenerative disease (e.g., the development of Lewy bodies, a common cause of dementia). ${ }^{10}$ Postmortem and functional imaging studies indicate that PDP has an anatomic and physiological signature associated with the disease process itself. A report of functional MRI examinations of patients without PDP who were experiencing hallucinations showed increased activity in frontal and temporal areas during hallucinations compared with nonhallucinating states. ${ }^{11}$ This is consistent with prior studies supporting the so-called "top-down" mechanism, in which anterior areas of visual integration supersede the posterior primary visual system. ${ }^{12}$ Postmortem examinations of the brains of PDP patients showed an increase of serotonin 5-HT2A receptors in regions of the frontotemporal cortex compared with brains of PD patients without hallucinations and also normal controls. ${ }^{13}$

The concept of PDP as a late occurrence in the course of $\mathrm{PD}$ is also undergoing reexamination. A recent publication reported the presence of hallucinations in patients with early and untreated PD, with some patients stating that, in retrospect, their hallucinations preceded the appearance of the motor manifestations of PD. ${ }^{14}$ The early appearance of hallucinations followed later by motor disturbances raises the question of an alternative diagnosis, such as dementia with Lewy bodies (DLB). However, the patients described in this report did not have dementia, and the DLB Consortium has revised diagnostic criteria for DLB and also proposed that the 1-year rule of the appearance of dementia as a discriminator between PD and DLB be discarded. ${ }^{15,16}$

A fundamental and ominous feature of PDP is its malignant course. Two longitudinal studies have found that, over time, symptoms that were initially of little or no concern became frightening or disruptive. ${ }^{17,18}$ The seemingly harmless, infrequent, and quizzical patient sightings of a child seated on the sofa or a dog lying on the kitchen floor are often indicators of serious trouble to come. Consequently, the notion of "benign hallucinations" is discouraged.

The symptoms of PDP have been recognized as a primary reason patients are removed from receiving care in their home and placed instead in a skilled nursing facility. ${ }^{6}$ Further, the presence of psychotic symptoms in patients with PD has been found to constitute an independent risk factor for death. ${ }^{19}$

Despite the frequent occurrence of PDP and the impact it has on patients and caregivers, patients with these symptoms do not necessarily report them to their health care providers or caregivers. One study revealed that among people identified to have hallucinations, $42 \%$ did not discuss them during their visits with their physicians, and in patients with delusions, 65\% did not address this symptom during their visits. ${ }^{20}$ The reasons for PDP not being addressed may be due to lack of recognition that these symptoms are part of $\mathrm{PD}$, the patient-perceived stigma of mental illness, or the challenge of addressing the numerous, troubling problems of PD in a timerestricted visit. Among the many and diverse symptoms of PD, neuropsychiatric symptoms may have the greatest impact on patient quality-of-life and caregiver burden and may therefore be of the highest priority to patients, caregivers, and clinicians in the management of PD. 4,21,22

\section{The Societal Burden of PDP}

The consequences of PDP can be devastating, with visits to emergency departments, hospitalizations, and removal of patients from their homes for placement in skilled nursing facilities. The economic impact of PDP on society is large and only adds to the substantial financial consequences of PD itself An analysis of a Medicare survey of claims data from 2000 to 2010 found that patients meeting a claims-based definition of PDP incurred much higher costs across various sites of care compared with patients without PDP; this analysis used a claims-based algorithm to identify potential PDP patients due to a lack of International Classification of Diseases, Ninth Revision, Clinical Modification (ICD-9-CM) code for PDP (data on file, ACADIA Pharmaceuticals, 2015). This analysis found that $74.6 \%$ of patients with PDP spent an average of 179 days in a long-term care facility, compared with $55.8 \%$ of PD patients without psychosis who averaged 83 days in a long-term care facility (data on file, ACADIA Pharmaceuticals, 2015). Among the non-PD patients in the cohort, $36.1 \%$ of patients who spent time in a long-term care facility were in a facility for an average of 22 days (data on file, ACADIA Pharmaceuticals, 2015). Annual all-cause reimbursement across all components of care for PDP patients averaged $\$ 67,251$ compared with $\$ 38,742$ for PD patients, and $\$ 18,757$ for patients without PD (data on file, ACADIA Pharmaceuticals, 2015). In skilled nursing facilities, annual all-cause reimbursement for PDP patients averaged $\$ 6,601$ compared with $\$ 2,067$ for patients with PD alone, but the highest cost differentials were seen in the long-term care setting, where patients with PDP had average annual all-cause reimbursement of $\$ 31,178$ compared with $\$ 14,461$ for patients with PD alone (data on file, ACADIA Pharmaceuticals, 2015). 


\section{PDP Treatment}

Despite the inconsistencies in literature that link PD medications to the symptoms of PDP, minimizing the effects of dopaminergic drugs and other contributing medications remains a central component of the initial PDP assessment and management process. However, addressing psychosis symptoms by reducing or eliminating medications that are intended to alleviate motor problems often results in the dilemma of choosing between an improvement in mobility or psychosis. Ideally, a management strategy would involve treatments that maintain or prevent worsening of motor issues while reducing hallucinations and delusions. Unfortunately, the majority of antipsychotic medications worsen motor symptoms of PD.

Prior to the approval of pimavanserin, treatment options for PDP were primarily limited to 2 antipsychotic medications: quetiapine (Seroquel) and clozapine (Clozaril). At lower doses, quetiapine and clozapine avoid the motor worsening that has been observed with other antipsychotics such as olanzapine (Zyprexa) and risperidone (Risperdal). ${ }^{23-25}$ Despite conflicting data from clinical trials demonstrating that quetiapine is effective in addressing PDP symptoms, quetiapine is currently the most widely prescribed medication in the United States for treatment of PDP. ${ }^{26-28}$ Although quetiapine may be beneficial for some patients with PDP, the inconclusive results coupled with the warning of increased risk of death in elderly patients with dementia is greatly concerning when considering the offlabel use of quetiapine in this setting.

In contrast, clozapine, which also carries an increased risk of death in elderly patients with dementia, has demonstrated efficacy in PDP in 2 well-organized trials. ${ }^{23,29}$ Despite its established efficacy, clozapine is infrequently prescribed for PDP, which is likely due to the perceived safety issues and frequent monitoring associated with its use. ${ }^{23}$ Clozapine carries a small risk of potentially fatal neutropenia, and because of this, patients receiving treatment with clozapine must undergo frequent monitoring, which can be burdensome and may present logistical challenges to patients, caregivers, providers, and dispensing pharmacies.

Based on serotonergic properties shared by earlier antipsychotic medications, pimavanserin was developed to treat PDP while also avoiding the dopamine interactions that worsen motor function in PD. ${ }^{30}$ The efficacy of pimavanserin was demonstrated in a pivotal trial that was the basis for its breakthrough designation in 2014, priority review status in 2015 , and subsequent FDA approval in 2016. ${ }^{30-32}$ To date, pimavanserin is the first and only medication approved by the FDA for the treatment of hallucinations and delusions associated with PDP.

The primary outcome measure of this pivotal, doubleblind, 6-week study was the 9-item SAPS-PD (Scale for the Assessment of Positive Symptoms-Parkinson's Disease), which was derived from the 20-item SAPS-H+D subscales (Scale

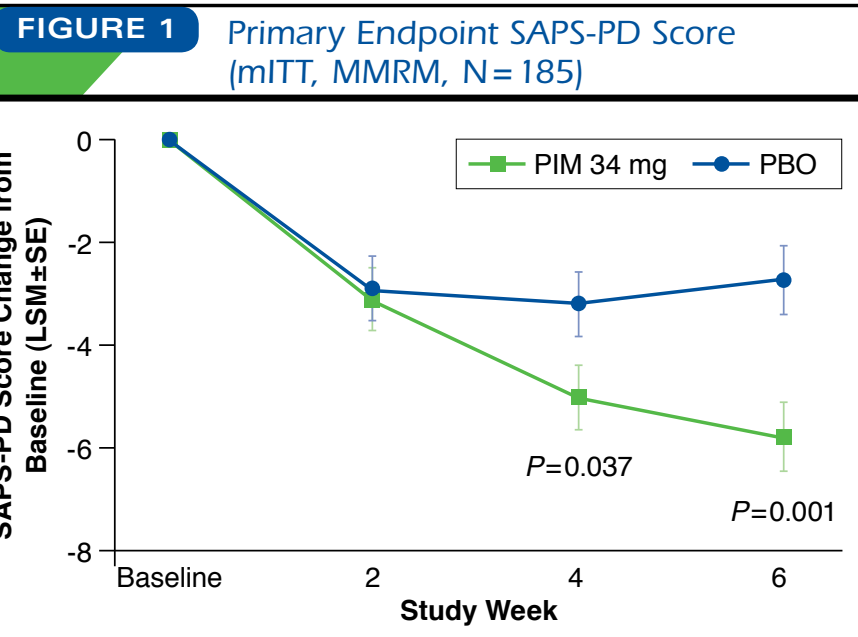

Adapted from Cummings J, Isaacson S, Mills $R$, et al. Pimavanserin for patients with Parkinson's disease psychosis: a randomised, placebo-controlled phase 3 trial, ${ }^{34}$ and Andreasen NC. Scale for the Assessment of Positive Symptoms (SAPS). ${ }^{40}$

LSM=least squared means; $m I T T=$ modified intention to treat; $M M R M=$ Mixed Model Repeated Measures Method; $P B O=$ placebo; $P I M=$ pimavanserin; SAPS-PD =Scale for the Assessment of Positive Symptoms-Parkinson's Disease; $S E=$ standard error.

for the Assessment of Positive Symptoms-Hallucinations and Delusions score) used in studies of schizophrenia. ${ }^{33} \mathrm{~A}$ secondary measure in the pimavanserin pivotal trial included the Unified Parkinson's Disease Rating Scale (UPDRS) Parts II + III to assess activities of daily living and the motor symptoms of PD. The results of the study demonstrated both statistically significant and clinically meaningful improvement of psychosis symptoms in the participants receiving pimavanserin over those receiving placebo (Figure 1). ${ }^{34}$ Among patients who received pimavanserin, approximately $74 \%$ experienced an improvement in PDP symptoms and nearly 14\% had complete resolution, compared with $56 \%$ and $1 \%$, respectively, for patients who received treatment with placebo. ${ }^{35}$

The UPDRS Parts II + III showed that there was no clinically meaningful difference in the activities of daily living and the motor symptom examinations of the patients taking pimavanserin when compared with the patients taking placebo. ${ }^{34}$ Adverse events that occurred in 6-week, placebo-controlled studies and that were reported at an incidence of $2 \%$ or more of participants and greater than those in placebo group included nausea, constipation, peripheral edema, gait disturbance, hallucinations, and confusional state (Table 1).35 As with all other antipsychotic medications, pimavanserin carries a boxed warning about risk of death in elderly people with dementia, although the warning differs from other antipsychotics in that it specifies that it is not approved for dementia-related psychosis unrelated to hallucinations and delusions associated 


\begin{tabular}{l|c|c}
\hline TABLE 1 & $\begin{array}{c}\text { Adverse Reactions in Placebo-Controlled } \\
\text { Studies of 6-Week Treatment Duration } \\
\text { and Reported in } \geq 2 \%\end{array}$ \\
& $\begin{array}{c}\text { Placebo } \\
(\mathbf{n}=\mathbf{2 3 1}, \boldsymbol{\%})\end{array}$ & $\begin{array}{c}\text { Pimavanserin } \mathbf{3 4} \mathbf{~ m g} \\
(\mathbf{n}=\mathbf{2 0 2}, \mathbf{\%})\end{array}$ \\
\hline Nausea & 4 & 7 \\
\hline Constipation & 3 & 4 \\
\hline Peripheral edema & 2 & 7 \\
\hline Gait disturbance & $<1$ & 2 \\
\hline Hallucinations & 3 & 6 \\
\hline Confusional state & 3 & 6 \\
\hline aHallucinations include visual, auditory, tactile, and somatic hallucinations.
\end{tabular}

with PDP. When using this drug within the approved labeling, pimavanserin may cause prolongation of the QT interval, which has also been observed with some antipsychotic medications at recommended doses, and certain antidepressants, antibiotics, and other medications. ${ }^{35-37}$

Dosing of pimavanserin is $34 \mathrm{mg}$ once daily (two $17 \mathrm{mg}$ tablets taken together). ${ }^{35}$ The half-life of pimavanserin is 57 hours, which is much longer than for both quetiapine (approximate mean-terminal half-life is 7 hours for quetiapine and 12 hours for its active metabolite, norquetiapine, within the clinical dose range) and clozapine (mean elimination half-life of 8 hours following a single $75 \mathrm{mg}$ dose and 12 hours after achieving steady state with $100 \mathrm{mg}$ twice-daily dosing). ${ }^{35,38,39}$ Additionally, pimavanserin requires a longer period, approximately 2 weeks, to achieve steady state plasma concentration. ${ }^{35}$ In the pivotal clinical trial, statistically significant improvement in SAPS-PD was observed between pimavanserin and placebo at the 4-week time point measurement (Figure 1). ${ }^{34}$

Pimavanserin is a $5-\mathrm{HT}_{2 \mathrm{~A}}$ inverse agonist/antagonist. ${ }^{35}$ This pharmacological action provides further validation for the role of serotonin in the symptoms of PDP. ${ }^{35}$ The priority review status of pimavanserin by the FDA has further underscored the impact of PDP and the unmet need in its treatment. The availability of pimavanserin has expanded the treatment choices for the management of PDP, for which limited treatment options previously existed. Since its approval, there have been various questions about the role of pimavanserin in the treatment of PDP, specifically regarding how it will be used by clinicians, accepted by patients and caregivers, and incorporated into the formularies of health plans.

\section{Panel Recommendations}

\section{PDP Diagnosis}

Recognizing the prevalence of PDP, its impact, and underdiagnosis, the panel recommends active and early engagement by health care providers with patients and caregivers regarding the symptoms of PDP and their relationship to PD. Early and frequent discussion has the potential to reduce the fear or stigma associated with PDP symptoms. It may also enable earlier recognition of PDP and reduce the likelihood of later complications. The frequency of discussion depends on the individual patient. For example, closer follow-up and inquiry of these symptoms are recommended for patients who acknowledge having symptoms, are experiencing them infrequently, have not found them disturbing, and are not receiving treatment for them.

Disorders other than PDP may mimic this condition and should be considered. Examples include delirium; substance abuse, including alcohol; or other psychoses unrelated to Parkinson's disease.

Summary of panel recommendations for PDP diagnosis:

- Early discussion of PDP symptoms with patients and caregivers, preferably at the time of PD treatment initiation

- Active inquiry about symptoms of PDP with patients and caregivers at intervals of 6 months or less

- Ruling out of other conditions (e.g., delirium, psychosis due to substance abuse, other psychiatric illness)

\section{Evaluation of New Onset or Abrupt Worsening of PDP}

For patients with PD and new onset PDP or an abrupt worsening of PDP symptoms, the panel recommends a careful review of medications and consideration of other acute or underlying illness as possible provocative factors. The panel emphasized that the medication review should not be restricted to only those used to treat PD, such as dopamine agonists or other PD treatments that may contribute to PDP symptoms. Rather, the review should be comprehensive and include all medications the patient is taking, as non-PD treatments may also cause behavioral disturbances. Examples of potential non-PD medications that may contribute to PDP symptoms include anticholinergic medications prescribed for urinary symptoms, such as oxybutynin, and diphenhydramine used as a sleep aid.

Laboratory testing and imaging should be considered according to the clinical evaluation, keeping in mind that patients with PD may be more susceptible to urinary tract and pulmonary infections, and their imbalance and risk for falls put them in danger of trauma, such as subdural hematomas. Lastly, the emergence or exacerbation of PDP symptoms, such as abrupt worsening of motor symptoms, may be a signal of a diagnosis unrelated to PD, such as a vascular event or an occult neoplasm.

Summary of panel recommendations for PDP evaluation:

- Review of all medications that may be contributing to PDP

- Reduction of dose or elimination of contributing medications when feasible and without compromising mobility

- Consideration of other exacerbating factors such as acute illness (e.g., urinary tract or other infection, subdural hematoma) 


\section{PDP Treatment with an Antipsychotic}

Following the aforementioned diagnostic and evaluation steps, the clinician is likely to begin the treatment selection process. The decision regarding when to initiate treatment requires a discussion between the provider, patient, and often, the patient's spouse/caregiver. This conversation should include a thorough history of the occurrence and frequency of hallucinations and delusions and their perceived impact on patient and caregiver quality of life currently and within the near future. PDP symptoms that are reported by the patient and caregiver to be infrequent and not disturbing do not necessarily require treatment, but the natural history of escalation of these symptoms should be given consideration, and a plan for treatment should be arranged to account for the potential for the PDP symptoms to become problematic before the next scheduled visit.

Once it has been established that treatment is necessary, the provider should discuss with the patient and caregiver the availability of treatment options, along with their associated potential benefits and risks, evidence for use, and FDA approval status or off-label use. The main pharmacological choices for therapy for PDP include pimavanserin, quetiapine, and clozapine. All 3 of these medications have a boxed warning regarding death in elderly people with dementia, and this warning must be made clear to patients and caregivers.

Although clinical decision making is often guided by experience, and appropriately so, evidence-based medicine is also of importance. Of concern to the panel members is the reliance on quetiapine as common practice when data from clinical trials have been mixed regarding efficacy. This creates a state of clinical trepidation when prescribing a medication with a caution of death for an off-label indication where the data for efficacy are inconclusive. Although clozapine has demonstrated efficacy in 2 well-organized studies, the burden of monitoring is often unacceptable to patients, caregivers, and providers. ${ }^{23,29}$

Summary of panel recommendations for PDP treatment:

- Discussion of prognosis of PDP with patient and caregiver (i.e., spontaneous resolution is unlikely, escalation is probable)

- Discussion with patient and caregiver regarding goals of treatment

- Discussion with patient and caregiver regarding duration of treatment

- Engagement of patient and caregiver in treatment selection by discussion of options, including

o FDA approval for PDP or off-label use

o Boxed warning of antipsychotic medications, including death in elderly patients with dementia

o Potential adverse effects from treatment options

o Rationale and requirements for clozapine monitoring, including blood tests and short prescription duration
- Assessment of treatment efficacy regularly and adjustment if needed

\section{Payer Considerations for PDP Management}

Because of the lack of an ICD-10-CM code for PDP, the identification of individual patients is a challenge. The current coding lacks the granularity for PDP and is either targeting general psychosis, PD alone, or PD with behavioral problems. This limits payers' ability to accurately assess the overall burden and cost of PDP.

Coverage of and access to PD treatments, including those for PDP, are controlled and delivered by payer-managed formularies and prescription benefit designs. The panel addressed that predictive information, such as associated risk factors and early recognition, may be of value to reduce the occurrence of PDP-related complications. The panel also noted that the payer source can influence treatment and access to care, as well as the degree of care coordination that may be offered to patients. Payers' focus is not limited only to medication-related costs, but to all costs of care. It is likely that contributing factors to PDP-related cost increases include emergency department evaluations and hospitalizations, with associated intervention by other specialists, and laboratory and imaging testing, prolonged hospital stay, and placement in a skilled nursing facility due directly to PDP symptoms.

It is plausible that earlier recognition and successful treatment of PDP will reduce payer costs substantially through a reduction in emergency department services, hospitalizations, and duration of stay, testing, and care provided in long-term facilities, along with other potential reductions in services. It is also possible that initiating treatment with a drug with established efficacy (i.e., pimavanserin), rather than off-label treatments without proven benefit, will more readily result in successful treatment outcomes and cost avoidance. The availability of pimavanserin presents payers with an opportunity to effectively manage patients with PDP.

Summary of panel recommendations for PDP medication management:

- Clinical support through medication therapy management (MTM) programs can be beneficial and effective for improving outcomes.

- MTM should be offered to patients with PD who have 3 or more comorbidities.

- Removal of medications for PDP that worsen motor symptoms of PD is suggested.

- Pimavanserin should be considered a first-line treatment for patients with an established diagnosis of PDP (i.e., FDA-indicated use of pimavanserin).

- Initial authorization of pimavanserin should be for 6 months to demonstrate clinical response. 
- Continued authorization of pimavanserin should be for 1 year, and requests for continuation of therapy should be accompanied by physician attestation of response to treatment.

- Pimavanserin treatment should be continued for a minimum of 6 weeks to assess efficacy.

- Semiquantitative assessment of pimavanserin efficacy should be performed by recording the frequency and severity of psychosis symptoms at the time of treatment initiation and after a minimum of 6 weeks of treatment.

- Attention should be given to concurrent medications that may cause QT prolongation.

- For patients deemed to be nonresponders to pimavanserin, consideration should then be given to its discontinuation and selection of other therapy.

\section{Future Considerations}

The panel emphasized that provider and payer education regarding PDP and the availability of pimavanserin are essential in order to achieve optimal treatment outcomes for these patients. One potential option to increase provider education is by offering continuing education programs. Recognizing that a broad group of providers are involved in the treatment of patients with PD, such education efforts will need to be directed toward neurologists, geriatricians, family medicine physicians, nurse practitioners, physician assistants, internists, psychiatrists, and psychiatry nurse practitioners. Patientdirected community education regarding PDP and pimavanserin is also essential to raise awareness of this condition, explain its association with PD, and inform patients about the availability of treatment options.

The panel members agreed that it would be valuable to have access to a scale for PDP that is validated, sensitive to change, and sufficiently simple that it could be incorporated into the time constraints of a patient visit. The panel members also noted that it is necessary to have longer-term data on the safety and efficacy of pimavanserin regarding disease progression, and there is substantial interest surrounding the impact of pimavanserin on use and costs.

Additionally, it would be helpful to payers to have a diagnostic code for PDP, as a code would allow payers to assess the impact of PDP on resource use. Finally, looking to the future and recognizing that health care is moving toward personalized medicine, pharmacokinetic testing and the pharmacokinetic profiles of treatments are anticipated to play a much larger role in identifying people who are at risk for PDP and selecting the most appropriate treatment for these individuals.

\section{Authors}

NEAL HERMANOWICZ, MD, Movement Disorders Program and Department of Neurology, University of California Irvine Health, Irvine, California; GUSTAVO ALVA, MD, Chapman Global Medical Center, Orange, California; ATP Clinical Research, Costa Mesa, California; and University of California, Riverside, Orange, California; FERNANDO PAGAN, MD, Department of Neurology; Movement Disorders Program; Georgetown University Hospital National Parkinsonism Foundation Center of Excellence; and Translational Neurotherapeutics Program, Georgetown University, Washington, DC; ALBERTO J. ESPAY, MD, MSc, Department of Neurology and Rehabilitation Medicine, University of Cincinnati Gardner Neuroscience Institute, Cincinnati, Ohio; AMITA PATEL, MD, CMC, MHA, CPE, Institute for Psychiatric Education, Dayton Psychiatric Association, Dayton, Ohio; KATYA CRUZ MADRID, $M D$, Academic Internal Medicine and Geriatrics, University of Illinois, and Jesse Brown Veterans' Center, Chicago, Illinois; DANIEL KREMENS, JD, MD, Movement Disorders Program and Department of Neurology, Jefferson University, Philadelphia, Pennsylvania; JIM KENNEY, RPh, Specialty and Pharmacy Contracts, Harvard Pilgrim Health Care, Quincy, Massachusetts; SHEILA ARQUETTE, RPh, Pharmacy Services, Independent Health, Buffalo, New York; and GARY TERESO, PharmD, BCPS, Health New England, Springfield, Massachusetts. MARIA LOPES, MD, and CAROLYN FARNUM, $B S$, Magellan Rx Management, Newport, Rhode Island.

CORRESPONDENCE: Lindsay Speicher, JD, Magellan Rx Management, 130 Bellevue Ave., Ste. 201, Newport, RI 02840. Tel.: 401.344.1105; E-mail: lspeicher@magellanhealth.com.

\section{DISCLOSURES}

This project and manuscript was funded by ACADIA Pharmaceuticals and developed by Magellan Rx Management. Lopes and Farnum are employees of Magellan Rx Management. Kremens has received consulting/speaker fees from Teva Pharmaceuticals, UCB, Sunovion, Impax, Lundbeck, ACADIA, USWorldMeds, Merz, Acorda, Kyowa, Neurocrine, and GE Healthcare. Pagan reports consulting/speaker fees from Teva Nanoscience, AbbVie, Impax, ACADIA, Medtronic, USWorldMeds, Merz, and Cynapsus and research and educational grants from USWorldMeds, Teva, and Medtronic. Patel has received consultant/speaker fees from ACADIA, Allergen, and Avanir. Alva reports research support from Accera, Allergan, Axovant, Eisai, Neurotrope, Genentech, Intra Cellular, Janssen, Lundbeck, Neurim, Novartis, Otsuka, Roche, Suven, and Trans Tech and consultant/speaker fees from ACADIA, Alkermes, Allergan, Avanir, Janssen, Lundbeck, Merck, Nestle, Otsuka, Sunovion, Takeda, and Vanda. The other authors report no potential conflicts of interest, financial or otherwise.

\section{REFERENCES}

1. Dorsey ER, Constantinescu R, Thompson JP, et al. Projected number of people with Parkinson disease in the most populous nations, 2005 through 2030. Neurology. 2007;68(5):384-86.

2. Olanow CW, Schapira AHV. Parkinson's disease and other movement disorders. In: Longo D, Fauci A, Kasper D, Hauser S, Jameson J, Loscalzo J, eds. Harrison's Principles of Internal Medicine. 18th ed. Vols. 1 and 2. New York: McGraw-Hill; 2012:3317-34. 
3. Ravina B, Marder K, Fernandez HH, et al. Diagnostic criteria for psychosis in Parkinson's disease: report of an NINDS, NIMH work group. Mov Disord. 2007;22(8):1061-68

4. Hermanowicz N, Edwards K. Parkinson's disease psychosis: symptoms, management, and economic burden. Am J Manag Care. 2015;

21(10 Suppl):s199-206

5. Klein C, Prokhorov T, Miniovitz A, Dobronevsky E, Rabey JM. Admission of Parkinsonian patients to a neurological ward in a community hospital. J Neural Transm (Vienna). 2009;116(11):1509-12.

6. Aarsland D, Larsen JP, Tandberg E, Laake K. Predictors of nursing home placement in Parkinson's disease: a population-based, prospective study. J Am Geriatr Soc. 2000;48(8):938-42.

7. Friedman JH. Parkinson disease psychosis: update. Behav Neurol. 2013;27(4):469-77

8. Divac N, Stojanović R, Savić Vujović K, Medić B, Damjanović A, Prostran M. The efficacy and safety of antipsychotic medications in the treatment of psychosis in patients with Parkinson's disease. Behav Neurol. Published online July 18, 2016. Available at: https://www.ncbi.nlm.nih.gov/ pmc/articles/PMC4967673/. Accessed June 7, 2017.

9. Goetz CG, Pappert EJ, Blasucci LM, et al. Intravenous levodopa in hallucinating Parkinson's disease patients: high-dose challenge does not precipitate hallucinations. Neurology. 1998;50(2):515-17.

10. Williams DR, Lees AJ. Visual hallucinations in the diagnosis of idiopathic Parkinson's disease: a retrospective autopsy study. Lancet. 2005;4(10):605-10.

11. Hoffman RE, Hampson M, Wu K, et al. Probing the pathophysiology of auditory/verbal hallucinations by combining functional magnetic resonance imaging and transcranial magnetic stimulation. Cereb Cortex. 2007;17(11):2733-43

12. Goldman, JG. New thoughts on thought disorders in Parkinson's disease: review of current research strategies and challenges. Parkinsons Dis. Published online March 2, 2011. Available at: https://www.ncbi.nlm.nih.gov/ pmc/articles/PMC3049364/. Accessed June 5, 2017.

13. Huot $\mathrm{P}$, Johnston $\mathrm{TH}$, Darr Tayyeba, et al. Increased $5-\mathrm{HT}_{2 \mathrm{~A}}$ receptors in the temporal cortex of parkinsonian patients with visual hallucinations. Mov Disord. 2010;25(10):1399-408

14. Pagonabarraga J, Martinez-Horta S, de Bobadilla F, et al. Minor hallucinations occur in drug-naive Parkinson's disease patients, even from the premotor phase. Mov Disord. 2016;31(1):45-52.

15. Emre M, Aarsland D, Brown R, et al. Clinical diagnostic criteria for dementia associated with Parkinson's disease. Mov Disord. 2007;22(12):1689-707.

16. McKeith IG, Dickson DW, Lowe J, et al. Diagnosis and management of dementia with Lewy bodies: third report of the DLB Consortium. Neurology. 2005;65(12):1863-72.

17. Goetz CG, Wuu J, Curgian LM, Leurgans S. Hallucinations and sleep disorders in PD: six-year prospective longitudinal study. Neurology. 2005;64(1):81-86.

18. Goetz CG, Fan W, Leurgans S, Bernard B, Stebbins GT. The malignant course of "benign hallucinations" in Parkinson disease. Arch Neurol. 2006;63(5):713-16.

19. Forsaa EB, Larsen JP, Wentzel-Larsen T, Alves G. What predicts mortality in Parkinson disease? A prospective population-based long-term study. Neurology. 2010;75(14):1270-76.

20. Chaudhuri KR, Prieto-Jurcynska C, Naidu Y, et al. The nondeclaration of nonmotor symptoms of Parkinson's disease to health care professionals: an international study using the nonmotor symptoms questionnaire. Mov Disord. 2010;25(6):704-09.

21. Zahodne LB, Fernandez HH. Course, prognosis, and management of psychosis in Parkinson's disease: are current treatments really effective? CNS Spectr. 2008;13(3 Suppl 4):26-33.
22. Gómez-Esteban JC, Tijero B, Somme J, et al. Impact of psychiatric symptoms and sleep disorders on the quality of life of patients with Parkinson's disease. J Neurol. 2011;258(3):494-99.

23. Parkinson Study Group. Low-dose clozapine for the treatment of druginduced psychosis in Parkinson's disease. N Engl J Med. 1999;340(10):757-63.

24. Ellis T, Cudkowicz ME, Sexton PM, Growdon JH. Clozapine and risperidone treatment of psychosis in Parkinson's disease. J Neuropsychiatry Clin Neurosci. 2000;12(3):364-69.

25. Weintraub D, Chen P, Ignacio RV, Mamikonyan E, Kales HC. Patterns and trends in antipsychotic prescribing for Parkinson disease psychosis. Arch Neurol. 2011;68(7):899-904.

26. Rabey JM, Prokhorov T, Miniovitz A, Dobronevsky E, Klein C. Effect of quetiapine in psychotic Parkinson's disease patients: a double-blind labeled study of 3 months' duration. Mov Disord. 2007;22(3):313-18.

27. Shotbolt P, Samuel M, David A. Quetiapine in the treatment of psychosis in Parkinson's disease. Ther Adv Neurol Disord. 2010;3(6):339-50.

28. Sarva H, Henchcliffe C. Evidence for the use of pimavanserin in the treatment of Parkinson's disease psychosis. Ther Adv Neurol Disord. 2016;9(6):462-73

29. Pollak P, Tison F, Rascol O, et al. Clozapine in drug induced psychosis in Parkinson's disease: a randomised, placebo controlled study with open follow up. J Neurol Neurosurg Psychiatry. 2004;75(5):689-95. Available at: http:// jnnp.bmj.com/content/jnnp/75/5/689.full.pdf. Accessed June 5, 2017.

30. U.S. Food and Drug Administration. FDA news release. FDA approves first drug to treat hallucinations and delusions associated with Parkinson's disease. April 29, 2016. Available at: http://www.fda.gov/NewsEvents/ Newsroom/PressAnnouncements/ucm498442.htm. Accessed June 5, 2017.

31. ACADIA Pharmaceuticals. Press release. ACADIA Pharmaceuticals receives FDA breakthrough therapy designation for NUPLAZID (pimavanserin) for Parkinson's disease psychosis. September 2, 2014. Available at: http://ir.acadia-pharm.com/phoenix.zhtml?c=125180\&p=irolnewsArticle\&ID=1962810. Accessed June 5, 2017.

32. ACADIA Pharmaceuticals. Press release. ACADIA Pharmaceuticals announces FDA priority review of NUPLAZID (pimavanserin) new drug application for Parkinson's disease psychosis. May 1, 2016. Available at: http://ir.acadia-pharm.com/phoenix.zhtml?c=125180\&p=irolnewsArticle\&ID=2105102. Accessed June 5, 2017.

33. Voss T, Bahr D, Cummings J, Mills R, Ravina B, Williams H Performance of a shortened Scale for Assessment for Positive Symptoms for Parkinson's disease psychosis. Parkinsonism Relat Disord. 2013;19(3):295-99.

34. Cummings J, Isaacson S, Mills R, et al. Pimavanserin for patients with Parkinson's disease psychosis: a randomised, placebo-controlled phase 3 trial. Lancet. 2014;383(9916):533-40.

35. NUPLAZID (pimavanserin) tablets for oral use. ACADIA Pharmaceutical. April 2016. Available at: https://www.accessdata.fda.gov/ drugsatfda_docs/label/2016/207318lbl.pdf. Accessed June 5, 2017

36. Harrigan EP, Miceli JJ, Anziano R, et al. A randomized evaluation of the effects of six antipsychotic agents on QTc, in the absence and presence of metabolic inhibition. J Clin Psychopharmacol. 2004;24(1):62-69.

37. Nachimuthu S, Assar MD, Schussler JM. Drug-induced QT interval prolongation: mechanisms and clinical management. Ther Adv Drug Saf. 2012;3(5):241-53

38. SEROQUEL XR (quetiapine fumarate) extended-release tablets, for oral use. AstraZeneca. Revised February 2017. Available at: http://www.azpicentral.com/seroquel-xr/seroquelxr.pdf. Accessed June 5, 2017.

39. CLOZARIL (clozapine) tablets, for oral use. HLS Therapeutics. Revised February 2017. Available at: http://clozaril.com/wp-content/themes/eyesite/ pi/Clozaril_PI.pdf. Accessed June 5, 2017.

40. Andreasen NC. Scale for the Assessment of Positive Symptoms (SAPS). Iowa City, IA: University of Iowa, College of Medicine; 1984. 



\section{Supplement}

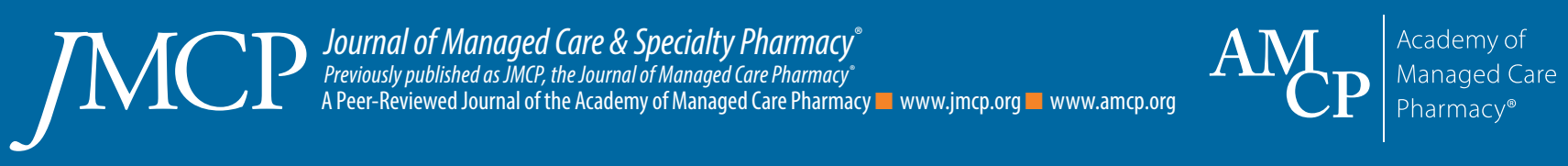

